\title{
The Influence of Early Experience on Personality Development
}

\author{
Mark H. Bickhard John Chambers Christopher
}

Key Words: cognition, early experience, implicitness, infancy, mind, object relations theory, ontology, personality, psychopathology, representation, substance

\author{
Mark H. Bickhard \\ Department of Psychology \\ 17 East Memorial Drive \\ Lehigh University \\ Bethlehem, PA 18015 \\ MHB0@LEHIGH.EDU \\ John Christopher \\ Department of Guidance and Counseling \\ College of Education \\ UOG Station \\ Mangilao, GU 96923
}




\title{
The Influence of Early Experience on Personality Development
}

\begin{abstract}
It is argued that theoretical approaches to the nature of the influence of early experience on personality development have been vitiated by incorrect metaphysical assumptions, of a sort historically characteristic of immature sciences. In particular, mind and mental phenomena are construed in terms of various sorts of substances and structures, instead of in terms of process ontologies. We show that these underlying metaphysical assumptions have prevented the most central problems of the influence of early experience from being addressed, and, therefore, from being answered as well. These aporia seriously infect such contemporary approaches as object relations theory, attachment theory, and cognitive behavioral theory. We outline an alternative process ontology of mind and intentionality - specifically, a process-functional ontology for representation - and explore the form of early influence offered within this new perspective.
\end{abstract}




\section{The Influence of Early Experience on Personality Development}

Models of personality development generally propose a strong influence of early experience on later personality. The manner in which that influence is proposed to occur, however, varies widely in accordance with differing basic assumptions concerning the nature of mind and development. In spite of this variety, we will argue that there is a common underlying assumption to these models, and, furthermore, that it is in error. This error is illustrated in such contemporary approaches as object relations theory, attachment theory, and cognitive behavioral theory. When corrected, not only is the assumption per se changed, but the basic question of early influence takes on a different form and so also does the nature of the answer. We present an adumbration of that new answer.

\section{Ontologies of Mind and Development}

Virtually every science has passed through at least one phase in which it considered the basic ontology of its subject matter to be some kind of substance or structure of substance (Hull, 1974). In most cases, these early notions have been replaced by realizations that the phenomena of interest are in fact phenomena of process and of patterns and organizations of process (Nicolis \& Prigogine, 1977; Prigogine, 1980; see also, Lucas, 1983, 1989; Schilpp, 1951 - the model outlined in this paper, however, is strictly naturalistic [Bickhard, in press-a], and has no convergences with, for example, Whitehead's pan-psychism). So, we find, for example, phlogiston theories of fire, caloric theories of heat, fluid theories of magnetism and of life, and so on, in each case now recognized to be in error, and replaced with process notions. In fact, the classic notion of substance has all but disappeared from contemporary science, to be found, perhaps, only at the level of the most fundamental particles. All else is constituted as stable, or unstable, hierarchical organizations of processes - quarks, nucleons, atoms, molecules, flames, living beings, and so on. Even at the level of fundamental "particles", however, the physicists' ontology is not so much one of particles, but rather of quantum fields, which also have a process character (Brown \& Harré, 1988; Teller, 1990). In any case, there is no support for simple substance notions at any level above subatomic particles.

What makes substance notions appealing is that many of the most important organizations of process in the world exhibit some sort of stability of organization, some sort of persistence through time, and that stability is precisely what is presupposed by the notions of substance and structure. Substances and structures are stable - inherently and, therefore, capture that critical property of stability: stability of existence in the case of substances, and stability of existence and organization in the case of structures. Unfortunately, they capture it by presupposing it rather than by explaining it, and, therefore, fail to address one of the most critical aspects of the subject matter - in fact, such presupposition of stability makes any issues of explanation of that stability at best obscure and at worst impossible. In consequence, the basic ontology and the basic understanding of that subject matter are distorted and incorrect.

As heuristic approaches, substance and structure heuristics are not necessarily problematic - in effect, they assume that explanations of the existence and organizational stabilities involved lie in some different domain or different level of analysis. If true, such assumptions can postpone addressing stability problems, or leave them for others to deal with. The explanation of the stability of water molecules, for example, is generally of only indirect relevance to analyses of its bulk properties; similarly, the metabolic stability of neurons may not be of direct relevance to the nature of neural interactions in mental 
processes, and, if so, the stable existence of neurons could be heuristically taken for granted in exploring mind instantiating brain processes - note, however, that such assumptions are at best heuristic assumptions, and could be false. Such heuristics, however, can yield problems if the stability explanations are at the same level of analysis as the phenomena of interest: flames and living beings are forms of stable open process systems, and their natures as flames or as living cannot be understood independently of those forms of stability. Substance and structure approaches to such phenomena yield circular eliminations of the basic issues, not explanations of them - such as phlogiston and vitalism.

Substance and structure heuristics are most dangerous in cases in which it is precisely the stabilities involved that are at issue. The stability presuppositions of substance and structure approaches cannot but obscure basic issues in such cases: stability presuppositions cannot but obscure the basic issues of stability. We will argue that it is precisely such issues of stability that are central to problems of the influence of early experience - the stability of early experience influences - and to problems of psychopathology - the stability of dysfunctionalities. In eliding the most central problematics of such phenomena, substance and structure approaches make genuine understanding of such phenomena impossible.

The unexamined and generally implicit substance and structure metaphysics of psychology renders this situation doubly problematic. Substance and structure heuristics already involve risks of diverting attention from, distorting, and obscuring central issues. The substance and structure metaphysics of psychology, however, renders even this heuristic approach as a presupposition - an implicit metaphysics — not as an explicit heuristic. Psychology, that is, is not even cognizant of the issues involved in such heuristics: there is no debate concerning the issues involved in such heuristics, no consideration of possible alternatives. In psychology, substance and structure approaches are not merely heuristically made assumptions concerning where relevant stability explanations lie, but are instead deeply implicit, therefore unexamined, metaphysical presuppositions.

The Stability of Early Influences. We will explore at least two senses in which the presupposition of stability in substance and structure notions, rather than the explanation of it, damages considerations of the influence of early experience on the development of the person. The first sense is that, if it is assumed that early experience establishes or changes early substance or structure, then the question of how those early influences persist into adulthood is never genuinely raised because the "answer" is presupposed and obvious: substances and structures are persistent, and, therefore, so also will be substances and structures established by early experience. Substance and structure notions, then, have an "aptness" for the noticed stability of early influence in that they presuppose such stability - but substance and structure notions, precisely because they presuppose stability, cannot be valid explanations for those stabilities. To propose such purported explanations is to use substance and structure notions to explain what they in fact already presuppose: it is to engage in circular explanation.

The Stability of Psychopathology. The second sense in which we will find such substance and structure presuppositions of stability to be damaging concerns the understanding and explanation of psychopathology. The issue here is not only one of how do the influences of early experience have stability through development and into adulthood in spite of all of the intervening experiences, but how does psychopathological functioning persist, manifest a striking stability, in spite of sometimes massive attempts to change on the part of the individuals involved. The argument does not need restatement - we have here a different version of the same problem: stability is the fundamental fact that needs 
explanation, and a substance or structural ontology of the mind and mental functioning simply presupposes that which needs to be explained.

The nature of these problems changes drastically if a process ontology of the person, of mind and learning and development, is accepted. If we recognize human beings as being intrinsically open systems - always interacting with their environments - and intrinsically self organizing systems - always modifying their forms of interaction through learning and development - then the stabilities of early influence and of psychopathological functioning become explicitly problematic, and no longer simply obvious and presupposed. How does a system that is continuously interacting and self organizing nevertheless manifest the stabilities of continuity from early influence and the stabilities of psychopathological rigidity? Stability must be explained, not presupposed.

\section{A Few Contemporary Approaches}

At this point, we will look at several approaches to this question. The problems in each case are variants of the basic "stability of structures" problem, so our discussion will largely focus on showing how these relatively familiar approaches do in fact manifest these problems. There is one form of the substance problem, however, that is relatively complex and of great importance on its own, and we will devote a little more attention to it. This is the problem of representation, and the manner in which it is distorted by a substance ontology approach.

Associationism. To begin, note that the classical associationistic learning approach is straightforwardly a substance approach. The underlying metaphor, in fact, is the classic waxed slate upon which the world impresses itself. Aside from the fact that such passivity of mind is false, the associationistic approach faces two problems stemming from its ontological assumptions. The first is simply the association version of the stability problem: Why do associations in fact tend to persist and be stable? If associations are taken to be primitive, such stability is presupposed, but not explained. The second problem derives from the sense in which the creation of associations is relatively independent of associations that might already be present. Associations are impressed from the environment, and new associations simply correspond to new (events in or elements of) environments. Under such conditions of free creation, why doesn't further learning of further associations through development obscure any influences from early experience? And, why can't psychopathological functioning be simply unlearned with new associations? Associationism, in other words, fails in both regards - the structural character of associations prevents their stability of existence from being explained, and their free creation prevents their stability of influence from being explained.

It might, perhaps, be countered that habits are not easy to unlearn, but are in fact quite difficult to change, and, thus, both problems of stability - of early influence and of psychopathology - can be addressed (though this does not address the problem of their free creation). Within the conceptual framework and vocabulary of this approach, these observations are quite correct, but as explanations, as counters to the questions, they are simply variants of the circularity of explanations mentioned above. They are question begging. To state that habits - associations - are difficult to change, and, therefore, exhibit a stability, is true, but that is precisely what needs explanation, and to further point out the fact does not provide such explanation.

Note that this critique is focused on the presuppositions of any theoretical language that takes associations as primitive. As such, it applies to all models that might be constructed using any such language. It is a similar generality of critique as was presented in Chomsky's point that associationism is logically inadequate to the facts of language - 
any associationistic model (Chomsky, 1964). It is a problem with associationism, not just with some particular associationistic models. On the other hand, a theory that took associations as phenomena to be explained, in terms of their existence, functioning, persistence, and other properties, would not necessarily be subject to this critique.

Classical Psychoanalysis. In the classic psychoanalytic view, there are several forms of substance and structure: a fluidic energy and paths of discharge of that energy, which, in turn, may involve structural representations. In this view, early experience serves to construct basic structural channels of energy discharge, and this includes the possibility of structural blockages to discharge and pools of undischarged energy (Rychlak, 1981; Sulloway, 1979). Such pools of energy may take the form of representations of persons or of experiences that are invested with, occupied by, "cathected" by, energy (Greenberg \& Mitchell, 1983). All of these notions are structural.

The structural channels and blockages and pools are therefore presumed to persist through development and into adulthood - and, thus, we have early influence - and the blocked and undischarged energies are presumed to be problematic in life, therefore dysfunctional, and, since they too are grounded in structures, they are difficult to change - hence psychopathology. The stability of the structures, however, is presupposed in the assumption that they are structures. It is not explained, and even that presupposed stability evaporates when structure is eschewed for process. Whatever descriptive metaphorical appeal these notions might be taken to have, they cannot serve as valid ultimate explanations.

A more contemporary version of psychoanalytic theorizing, object relations theory, makes much more intrinsic use of the notion of representation - although it also retains that of an energy or of an energy-like affect which can be invested in, resident in, dedicated to, "cathected" in (i.e., occupied by - or some other metaphor) representations. Before addressing this approach, then, we will briefly outline some of the special problems that occur when a substance approach is taken to representation.

Encodingism: A Failed Model of Representation. A substance and structural approach to representation raises the basic questions of what sort of substances and structures can be representations, and how they accomplish representation. A classic approach to the answers took pictures and statues as the basic metaphors, and concluded that they represent by virtue of some sort of similarity to that which they represent. Similarity, however, has proven to be an inadequate ground for representation (Fodor, Bever, \& Garrett, 1974). It has an appeal for supposed perceptual pictures of the world, but fails for general concepts - which triangle is the general "triangle-representation" supposed to be similar to, or equivalently for the notion of "chair"? - and fails miserably for abstract concepts - how can a representation be similar to a virtue or to "democracy"?

A more contemporary version of this substance and structure approach is that of encodings, such as Morse code or computer codes. Encoding approaches to representation, in the form of information processing or symbol manipulation models, dominate contemporary cognitive science. Such encodings clearly exist (so also do pictures and statues), and the presumption is that all representations have this general form. Encodings, however, are stand-ins for other representations: "..." stands-in for "S" in Morse code, while a bit pattern stands-in for "S" in a computer code. Such stand-in relationships can be enormously useful because new things can be done with and to the stand-ins that cannot be done with or to that which is used to define the encoding: "S" cannot be sent over a telegraph wire, but "..." or a bit pattern can be. Such stand-ins, however, require some other representation to serve as the base for the encoding. Encodings provide new forms for already present representations, or for newly defined 
combinations of already present representations. Encodings do not provide a model of the emergence of representation out of underlying process (or structure) that is not already representational. Encodingism approaches cannot explain the emergence of new representations.

This fact about encodings has not gone unnoticed, but, when it is understood, it is taken as an intrinsic property of representation per se, and is not seen as a limitation of the encoding, the structural, approach to representation (Bickhard, 1980a, 1991a, b, c; Campbell \& Bickhard, 1987). The inability of encodings to address the fundamental problem of emergence of representation is the foundation of several additional inadequacies. Since encodings cannot emerge out of non-representational phenomena, a strict encodingism forces a viciously circular logic in which representations of something must already be present before they can be obtained. This circularity vitiates any purported adequacy of the general encoding approach, and underlies these additional inadequacies.

For example, to check on whether or not an encoding representation is accurate requires that it be checked against that which it is taken to represent. By the assumption of encodingism, however, the only access available to the represented is via the encoding representation. To check such a representation, therefore, is to check it circularly against itself, which is no check at all. The conclusion is that we can never have grounded knowledge - we can never have any real idea of whether or not we are correct in our representations. This is the classic argument of skepticism, and it has resisted all attempts at its dissolution over several millennia (Annas \& Barnes, 1985; Burnyeat, 1983; Popkin, 1979). We suggest that it is in fact indissoluble because it is valid, but that it only applies to encoding models of representation (Bickhard, 1987, 1991c, in press-a).

Another version of this circularity is the problem, not of accuracy, but of construction. The basic point is that we must already know what it is that needs representing before we can construct encodings of it, but, since we can only know the world in terms of those encodings, we can never determine which encodings to construct (Piaget, 1970). We have to already represent the world before we can construct our representations of the world.

Still another version of this circularity is the problem of definition: how can we know what an encoding is supposed to represent at all, even prior to the questions of whether it is correct or of whether or not to construct it. For standard encodings, the answer is, simply, in terms of whatever other representations are used to define the given encodings. Those encodings in turn might be defined in terms of still others, and so on. This regress, however, must stop at some point, and here is where the problem occurs. If we ask of such a grounding, foundational, encoding "How do we know what it is to represent?" no answer is possible. If it is defined in terms of some other representations, then it is not at that foundational level, contrary to assumption. If it is defined in terms of itself — the only remaining possibility — we have something like "' $\mathbf{X}$ ' represents the same thing as does ' $\mathbf{X}^{\prime \prime}$. This provides no representational definition at all. The notion of a foundational encoding is logically incoherent (Bickhard, 1980a, 1987, 1991c, 1992a, in press-a; Bickhard \& Terveen, 1992). Note that the incoherence is a functional view on the problem of the impossibility of the emergence of encodings: it is precisely at this foundational level that such emergence would have to occur, and it is, therefore, here that we encounter the impossibility of that emergence within encodingism.

One sense of the importance of these failings of encodings is to note that, as standins, encodings can not provide new knowledge; they can only stand-in for representation already available. Encodings are necessarily $\boldsymbol{r e}$-codings (except a first level, which must be stand-ins for some other form of representation). But, if encodings cannot provide new 
knowledge, then they cannot provide knowledge to a mind about the environment in perception, nor can they provide knowledge to a second mind about the contents of an utterer's mind via the decoding of linguistic utterances - neither perception nor language can be fundamentally a matter of encodings. Most broadly, in being incompetent to yield new knowledge, encodings cannot perform any of the standard epistemological tasks for which they are ubiquitously proposed or presupposed (Bickhard, 1980a, 1987, 1991c, $1992 \mathrm{a}$, in press-a, in press-b).

Encodingism is only occasionally an explicit proposal for the nature of representation (Palmer, 1978). More commonly it is presupposed, sometimes in very subtle ways. The most common approach to representation is to assume that representations must be some version of elements internal to an epistemic system that are in covarying correspondence with some things or properties in the environment, and that those elements represent those things in the environment by virtue of such correspondence. Such correspondences might be set up by sensory transduction, perceptual processing, cognitive inferences, and so on. There are many problems internal to this perspective on representation. One is that, if an internal element is in correspondence with something in the environment, it will also be in correspondence with myriads of other things in the environment - a neural impulse in the optic pathway in correspondence with some object will also be in correspondence with chemical activities in the retina, with patterns in the light, with electron orbitals in the surface of the object, with the history of the object, and so on - so which correspondence is the representational one? Another problem is that, if representation is constituted by correspondence, then representation exists if and only if such correspondence exists - so how could representation ever be wrong? If the element is in correspondence, then that is what it represents, while if it is not in correspondence, then it is not a representation. Error is impossible in this framework (for some of these struggles, see Fodor, 1987, 1990; Loewer \& Rey, 1991; Bickhard, in press-a).

There are many more problems internal to encodingism, but the most important problem is an external one: for a correspondence to provide representational knowledge to an organism, the organism has to already know that the correspondence exists, and what the correspondence is with. Correspondences per se are everywhere, and they are free every physical law, for example, provides unbounded numbers of correspondences between initial and final conditions throughout the instances of those laws everywhere in the universe. It is only, or at best, known correspondences that can yield representation for an epistemic agent but that constraint completely reintroduces all the circularities of encodingism - I must already know both the fact and the other end of the "...." to "S" correspondence in order for "..." to be a representation for me; I must already know what is being "stood-in-for". The representational contents must already be available representations of the fact of the correspondence, and of what the correspondence is with - in order for correspondence to yield representation for the agent, so this correspondence approach presupposes the very phenomena of representation that it purports to explain. Once again, encodingism requires that representation be already available in order for representation to exist.

There are many more problems and many more arguments (Bickhard, 1980a, 1991c, 1992a, in press-a, in press-b; Bickhard \& Terveen, 1992), but the critical point for our purposes is that encoding elements are not viable candidates for explaining the representational competencies of infant and adult human beings, or of any other animals, or of robots, or of creatures on other planets - encodings are epistemologically incompetent. They can only stand-in for representation that is already available. Encodingism is not only wrong and impossible, it is also extremely distorting and misleading. 
Encodingism constitutes a substance approach to representation. First, encodingism is historically a product of generalization and sophistication from initially straightforward substance approaches, with pictures and statues — and waxed slates - as the basic metaphoric exemplars. More deeply, however, encodingism carries its substance metaphysics in its presuppositions that representational contents are inherently stable and that they cannot come into being out of non-representational phenomena. Basic encodings are fundamental - metaphysical - representational atoms: they are not created de novo, they are not emergents. Since it cannot be emergent, encoding representational content must come from somewhere. If encoding content is presumed to come from the environment, we have classical and contemporary empiricism, while if it is presumed to come from the genes, we have contemporary rationalism. In either case, the existence and the stability of encodingist representational contents are not subject to analysis from within the encodingist framework - the existence and stability of encoding atoms are instead presupposed in the encodingist metaphysics. The substance commitments of encodingism, with its presuppositions of stability and impossibility of emergence, is but one aspect of the several aporias of encodingism - but these metaphysical presuppositions are corollaries of other aspects, such as the incoherence problem. In particular, the incoherence problem makes it impossible for encodingist atoms to come into being within the framework of encodingism, because there is no way to provide them with the representational content that would make them encodings in the first place from within the framework of encodingism, and encodingism simply elevates that impossibility to an unexamined metaphysical presupposition.

Object Relations Theory. The relevance of this discussion of representation is that object relations theories, among many others, make theoretically essential use of concepts of representation, and universally do so from within an encodingist, a structural, perspective. They thus not only encounter the logical incoherences and impossibilities mentioned above, but they are also led to positions that are contradicted by contemporary evidence concerning cognition and development (Harris, 1983).

Object relations theories attempt to explain the influence of early experience on development in terms of the internalization of representations of that experience, with an emphasis on the other persons, the "objects", involved. These earliest representations are presumed to be of various actual (or fantasized) experiences, sometimes explicitly in terms of memory traces, and generally with some affective or energetic investment associated with the emotional aspect of the experience. Various means and developmental paths are proposed for the construction of higher order structures out of these foundational memories, with the optimal end-point of integrated representations of the self and of the other (Eagle, 1984; Greenberg \& Mitchell, 1983; Reppen, 1985). 1992b):

There are a number of fundamental problems with these approaches (Bickhard,

o First, they directly encounter the incoherence of encoding notions of representation mentioned above.

o Second, the means of construction are metaphorical and unclear.

o Third, the constructions out of memories are presumed to generate representations of general concepts and universals, such as of others and of the self and of their properties, and no explication is offered of how this impossibility is accomplished - you can't get a generic triangle or chair out of combinations of specific triangles or chairs (Fodor, Bever, \& Garrett, 1974). 
o Fourth, the presumed end-point of a representation of the self, even overlooking that there is in fact no way of getting there from the proposed ground of memories, is then taken to actually be the self - a blatant non-sequitur and inconsistency: a representation of something is not the thing itself (e.g., Kernberg's model in Greenberg \& Mitchell, 1983, p. 335).

o Fifth, adult cognitions do not have these properties - e.g., higher level cognitions are not constructed out of memories as building blocks.

o Sixth, infants cannot represent or remember singular memories, and cannot represent or remember other persons or selves - these are cognitive capacities that are far beyond the capabilities of neonates, and that do not develop till some months and years later (Bickhard, 1992c; Gratch, 1977; Nelson, 1992; Piaget, 1971; Piaget \& Inhelder, 1969; Tulving, 1985). Thus, there is no cognitive ground for this approach to the influence of early experience - babies cannot do what they are theorized to do (Christopher \& Bickhard, in press, 1992b; Christopher, Bickhard, \& Lambeth, in press).

This point returns us to the basic theme of the discussion. Object relations theories propose a model of the influence of early experience on later development, including psychopathological development, in terms of memories of experiences with significant others and the constructions out of those memories. The stability of influence is presupposed in the structural character of those memories and constructed representations.

The general approach, however, suffers from the logical incoherence of the general approach to representation, the unclarity of the constructions involved and the impossibility of the supposed representations constructed, the failure of the central claimed construction (of representations of the self) to be what it is purported to be (the self), and the empirical falsity of the presumed foundational event representations and memories in infancy. Some of these problems - e.g., the confusion between a representation of the self and the self per se - are problems in simple logic, but most of them are in one way or another manifestations of the underlying substance and structural approach to representation and development. Early experiences are posited to create atomic structural memories which are combined to produce higher level structures. Neither the problem of early influence nor the problem of psychopathology can ultimately be solved within this framework.

Attachment Theory. An approach to the problem of early influence with strong relationships to the psychoanalytic tradition is that of attachment theory. There are many interesting and important aspects to attachment theory, but the point that we wish to make in this context is by now familiar. The presumed influence of early experience on later development within attachment theory is in terms of "internal working models" of relationships, constructed on the basis of those early experiences (Bowlby, 1973, 1982; Bretherton, Ridgeway, \& Cassidy, 1990; Kobak \& Sceery, 1988). This has much to recommend it from a descriptive perspective, but the internal working models are structural encodings in both presumed origin and presumed nature, and, thus, encounter the myriad problems of logic and fact mentioned above.

Cognitive Behavior Theory. A rival approach to the analytic schools is that of cognitive behavior theory. This approach has progressed beyond the simple associationism of early learning theory to a positing of a fundamental role of cognitive elements such as beliefs. These cognitive elements are presumably constructed early in life, and it is their irrationality or dysfunctionality that underlies psychopathology. Of course, it is also their structural character that implicitly accounts for the persistence of early experience into adulthood and for the difficulty of change of psychopathology. 
There are several versions of this approach, just as for the object relations approach. The basic ontology of one version is that of beliefs - irrational beliefs in particular (Ellis, 1962). Another general approach posits sentences that are somehow resident and spoken in the mind - self talk - dysfunctional self talk in particular (Meichenbaum, 1977). Equivalently, those sentences, perhaps abbreviated, might be construed as an autonomous flow in the mind - automatic thought - distorted automatic thought in particular (Beck, 1976; Beck \& Weishaar, 1989). The ontologies and the developmental models of these positions tend not to be as elaborated as those of the psychoanalytic schools, but, nevertheless, the underlying ontological assumptions of substance and structure - beliefs and sentences, in these cases - are similar. Moreover, the sense in which the basic problems of developmental continuity and of psychopathological rigidity are presupposed rather than explained in these structural approaches is the same in cognitive behavior theory as in object relations theory. So also are the structural encoding assumptions concerning the nature of representation, with their myriad problems of skepticism and incoherence.

Structural approaches, then, are ubiquitous. As such, they cannot explanatorily address two of the fundamental problems of personality development - the influence of early experience on later development, and the rigidity of psychopathological functioning. They presuppose rather than explain these critical aspects of human functioning.

Any correction of these approaches must first begin with an alternative to the underlying problem - an alternative to the basic substance and structural assumptions concerning mind and development. In particular, it must take seriously the clear open system interactive character of life and mind, and the intrinsic self organizing character of learning and development.

\section{Representation and Development as viewed from within A Process Ontology of the Mind}

There are two basic aspects of the alternative model of mental functioning that will be particularly needed to address the influence of early experience on development. These are the general character of representation from a process perspective, a process metaphysics, and a notion of the nature of development. These aspects of the overall model will be outlined, at which point we will return to the original questions. We will find that those questions have changed somewhat — in fact, some new questions emerge — and that the answers are unfamiliar.

Interactivism. The process model of representation that we wish to outline is called interactivism. The basic notion of interactive representation is that goal-directed open systems need to be able to differentiate their interactive processes in the service of the active goals and in accordance with appropriate differentiations of the environment: - they need to be environmentally sensitive, and such sensitivity requires differentiations of system activity in response to differentiations of environmental conditions. ${ }^{1}$ Some paramecia, for

1 Here we are making the heuristic assumption that the existence and stability of such systems, and of their functional organizations, are explicable at lower levels of analysis. We are suggesting an account of representation as emergent in certain functional system organizations, taking such systems and functional organizations as primitive for the purposes of this account. On short time scales, such independent stabilities seem clear akin to the stability of the functional organization of a program in a computer. On longer time scales, this does not hold, since the stability of the organism and of a species is itself 
example, tumble in some environments and swim relatively straight ahead in others; they tumble when swimming is yielding decreases in desirables (such as sugar concentration) or increases in noxiousness - when things are getting worse - and they swim so long as desirables are increasing or noxiousness decreasing — so long as things are getting better. That is, paramecia differentiate tumble situations from swim situations, and thereby tend to approach food and avoid poison (Campbell, 1974).

Note that the factual correspondences involved for the paramecia are with food and poison gradients, but that those "other ends of the correspondences" are not what is represented for the paramecium. What is represented, what is functionally accessible, is the potential for apt tumbling or for apt swimming. For a paramecium, such representations of potential action are always enacted; for a frog, however, indications of the potentiality for tongue-flicking-and-eating — involving, perhaps, a factual correspondence of neural activity with a fly - may be ignored if there is also indication of flee-and-hide - involving, perhaps, a factual correspondence of neural activity with a bird of prey. That is, in general, indications of the potentiality for interaction may or may not be actualized. The core of the proposal, then, is that representational contents are constituted as indications of potentialities for further interaction with the environment, not as transduced correspondences with, and from, the environment. Representational content is emergent out of (potential) action (Piaget, 1971; but see Bickhard, 1988; Bickhard \& Campbell, 1989, for some fundamental differences), not out of the passive processing of inputs. This yields a functional notion of representation, rather than an encodingcorrespondence notion (though it is possible in principle for internal derivative encodings to serve these functions of differentiation of system activities, see Bickhard \& Richie, 1983).

The key to the difference is the recognition that the grounding differentiations of the environment do not need to be themselves encodings. The internal course of an interaction between the system and an environment will depend both on the organization of the system and on the environment. In particular, in some environments, the interaction will result in one sort of final internal condition when the interaction is completed, while other environments will result in differing final internal states. These differences in final internal states resulting from interactions serve to differentiate possible environments into categories - those that yield this final state differentiated from those that yield some other final state. These environmental differentiations, in turn, can differentiate further system interactive activity. Thus, we have a form of functional representation in the above sense, but those initial environmental differentiations do not and can not constitute encodings.

The reason is simply that the final states do not represent anything about the categories of environments that they serve to differentiate. There is no representational content here. If an attempt were made to consider the final states as encodings, there would be no way to specify what they represented - the attempt would fail. Yet the functional tasks of differentiating the environment in the service of differentiations of further system interactions can be served.

There are many questions about representation that this leaves unaddressed: How, more specifically, does representational content arise? What about the representations of mathematics or of other abstract domains of knowledge for which there is no environment to interact with? What could language be within this perspective? These questions are

in part explicable only in terms of the cognitive capacities of the organisms involved. On such longer time scales, cognition must be an aspect of biology and evolution, not just grounded upon it (e.g., Piaget, 1971). For some contributions to the more general issues here, see Bickhard, (in press-a). 
addressed elsewhere (Bickhard, 1980a, 1987, 1992a; Bickhard \& Campbell, 1992;

Bickhard \& Richie, 1983; Bickhard \& Terveen, 1992; Campbell \& Bickhard, 1986; 1992); for our purposes here, the important point is that there is a ground form of representation that is functional rather than structural in nature and that does not encounter the incoherencies of encodingism. Note, in particular, that the representational functions of environmental and system activity differentiations are emergent from system organization. They do not require that representation already exist in order for representation to come into being.

An intuition of a strictly functional sense of representation can be derived from consideration of a mechanical bug on wheels that is controlled by a computer program (with no encoded data structure). If the program is organized correctly, the bug can run around in a room without bumping into either furniture or walls. The organization of the program, then, contains information about the layout of the room, but not in encoded form - it is instead implicit in the functional organization of the system. A further demonstration of this derives from now assuming that the same program organization controls a pen on paper instead of the bug itself - that pen can now trace outlines of the walls and obstacles of the room, again without any necessity of explicit encoded symbols. This sense in which system functional organization can constitute representational information about the system's environment without encoding that information is one of the key aspects - the selection of further activity aspect - of the interactive notion of representation.

Interactivism: Constructivist Learning and Development. From an encoding perspective, representation is constituted as certain forms of structural correspondences between the encoding structures and that which they encode. In this view, it is tempting to posit that those structures are somehow impressed into a passive mind, a waxed slate, from encounters with that which is to be represented - the structural correspondences would then follow automatically. Synchronic versions of this conception are often called "transduction" (Fodor \& Pylyshyn, 1981), while diachronic versions are called "induction". In the interactive view, representation is not a matter of structural relationships at all, but, rather, of functional process relationships between system and environment. The system organization that manifests those functional interactive relationships need have no particular structural relationships with the represented at all. Thus, in this view, there is no possibility that representations will be impressed from outside into a passive mind.

In other words, interactivism logically forces a constructivism. Furthermore, since prescience is impossible and circular as an epistemic requirement, those constructions must have - in the logical limit — the character of blind variations that are tried out against the selection pressures of satisfactorily serving the goal directedness of the interactions. Most actual variations, of course, will not be totally blind, but instead will make use of heuristics concerning what sorts of problem solutions might be useful to try out in given situations. Those heuristics, however, themselves constitute knowledge, and the origin of that knowledge also will ultimately be traceable to blind variations and selections, in some cases at the evolutionary level (Bickhard, 1987, 1992a; Bickhard \& Campbell, 1989; D. Campbell, 1974).

Interactivism as a model of representation, then, not only forces a constructivism, it forces a variation and selection constructivism. These two properties - that representation is a functional aspect of interactive system organization, and that learning and development intrinsically involve constructive variations and selections - are what will be needed to return to the basic questions of the influence of early experience, and that of psychopathological rigidity. 


\section{Early Influence}

The question of early influence on later development breaks into two parts with respect to the interactivism model. The first question is: How can early influence have any relevance for the level of issues concerning life and the self and others? The reason for this question is that, superficially, the interactive model provides nothing to be influenced at early ages except system functional organization - whence, then, comes any relevance to the self, and so on? Even disregarding interactivism per se, this question arises anyway since the evidence on infant cognition does not give any grounds for the high level cognitions and memories of self and others (Bickhard, 1992c; Nelson, 1992; Tulving, 1985) that are commonly postulated as being influenced from early experiences. This point, in fact, is one of the several grounds for rejecting the adequacy of contemporary object relations theory.

More specifically, interactivism — consistent with cognitive development provides little more than functional system organization to be influenced at early ages. Even allowing that interactivism provides a sense in which system functional organization can constitute emergent representation, there is no ground for postulating representations of high level, such as of the self or other persons, at the early ages involved. If system organization is all that can be influenced, because it is all that is present to be influenced, how do those influences have any relevance for later personality development?

The first part of the early influence problem, then, is concerned with the question of how such early influences on system organization can have relevance at the level of personality, given that personality issues as usually conceived involve issues beyond the cognitive capacities of infants. The second part of the answer address the question of how such early influences, even if they have in some sense relevance for higher level personality issues, manage to have the stability of influence over the course of development that is required to affect adult personality.

Manifested Properties. The first step in the answer to the question of relevance lies in the realization that systems can have properties, can instantiate properties, without those properties being actual or present inside the systems themselves - there can be truths about systems that are not parts or components or elements of systems. One class of examples for this point is simply the category of system relational properties - properties of how the system relates to its environment. A computer program, for example, can be fast or awkward or aggravating to use, without "fastness" or "awkwardness" or "aggravating" being locatable anywhere in the program. For human beings, this category includes the fundamentally important cases of creating social realities that we are not aware of creating, and that are unintended side effects of whatever our actual intentions and actions might be. An individual, for example, might be generally annoying to others, or distancing, without either "annoy" or "distance" being goals or intentions or desires of the individual involved. Note that, typically, the tendency is to speculate that "annoy" or "distance" is explicit as a goal for the individual, and his or her lack of awareness of the goal is explained by locating that goal in the Unconscious.

Implicitness. For our purposes, an even more important class of examples of manifested properties involves a sense in which properties may be implicitly true of a system without being actual in the system. We approach these phenomena of implicitness beginning with language, then move toward examples involving human beings. The sentence "The king of France is bald." presupposes that France has a king — a presupposition that in this case is false. This presupposition is a kind of condition for the "well functioning" of the sentence - without it, the sentence is inappropriate in some sense. Philosophers of language argue about the precise form of failure of such sentences, 
but the important point for our purposes is simply that presuppositions exist, whether true or false. Note that a presupposition is not the same as an implication: a sentence and its negation cannot have the same implications, yet both "The king of France is bald" and "The king of France is not bald" involve the (false in this case) presupposition that France has a king.

This sense in which sentences involve conditions that are presupposed for their "well functioning" is also true for goal directed systems. A thermostat, for example, implicitly presupposes that the heat flow in or out of the room will not exceed a certain rate, otherwise the capacity of the system will be exceeded, and it presupposes that the cycling between too hot and too cold will not exceed a certain frequency, otherwise the switching mechanism in the thermostat will not be able to keep up. These are both presuppositions in the design and functioning of the thermostat, but neither is present in the thermostat - they are not inscribed on the wires, for example. Certainly they are not beliefs or explicit assumptions of the thermostat. Yet they are implicit presuppositions of the functioning of the thermostat, of the functional relationships between the thermostat and its environment. They are implicitly presupposed in that only in such conditions will the thermostat function successfully with respect to its internal criterion of achieving and maintaining its set point temperature. Implicit presuppositions, then, are conditions for apt functioning.

The key here is that we have a case of implicit presuppositions, functional presuppositions, in a system - a thermostat — that has no cognitive capacities at all. Conditions for apt functioning do not have to be represented in order to be manifested as presuppositions. There should be no problem in principle, then, in the notion that the functioning of infants will involve implicit presuppositions, in spite of their limited cognitive capacities.

Consider, for example, an infant boy who is physically taken care of, but is attended to in a way that is totally non-responsive to him per se. He is fed, changed, etc. on a schedule and by the rules, but his cries - his potential interactions with the world are ignored. This infant will likely learn that crying only increases discomfort, will learn 'quietude' as the only coping that is effective in minimizing, if not correcting, his pains and discomforts. This learning will take place on a cognitively primitive level - there need be nothing more than a learning of a new way of being, "quietude", as the only one discovered that "works", that reduces discomfort. In other words, this may be the only functional organization that he has tried that has survived selection pressures. Nevertheless, this way of being carries implicitly the presupposition that no one truly cares about him, that no one is concerned about him as something beyond his physical needs.

Such implicit presuppositions of his way of being in the world can be true of his functioning even though he is totally incapable of having any of the explicit cognitions that might seem to be involved in those presuppositions - he may be too young to be able to conceive of anything like caring or even about other persons as objects and agents in the world. Nevertheless, such presuppositions can be implicit in his way of being. Thermostats are certainly incapable of cognizing their functional presuppositions, which are nevertheless certainly present.

In the example, this level of presupposition is in fact true not only as a presupposition of the infant, but also of the environment he happens to be in. But the child cannot at such an age differentiate this condition, this environment, these "caregivers", from any others. This way of being is central to who he is, it is not just a differentiated adjustment to this particular situation. As such, this way of being is implicitly about the entire world, actual and potential, not just this part of it into which he has been "thrown". The lack of differentiation of this way of being with respect to alternative possible 
environments implicitly presupposes not only that no one is caring for him, but that no one would ever care for him. A lack of differentiation of this situation from others, of these caregivers from others, implicitly presupposes totality, again without any explicit cognitions or cognitive capabilities on the part of the infant.

This example also illustrates another important property of presuppositions: presuppositions can themselves have presuppositions. So, for example, "France has a King" presupposes that France exists. And the infant's presupposition that no one would ever care for him presupposes that he is not worthy of being cared for, that he is inadequate in some fundamental way, that he is not deserving of, is not a full member of, humanity. That is, a way of being can have layers of implicit presuppositions, and sufficiently deep layers of implicitness can involve presuppositions about the self - implicitly. In this example, the infant may have no explicit sense of self whatsoever, and be developmentally incapable of such cognition, and yet critical presuppositions concerning the self and others may be already implicitly present.

Implicitness, then, provides an answer to the question of how early experience could have any relevance to personality issues if, in fact, the cognitive capacities of the infant are not yet adequate to explicitly constitute or represent the core issues of personality. The infant can learn and develop ways of being in the world that involve implicit presuppositions about core personality issues that are far advanced beyond the infant's actual cognitive capacities. Implicit presuppositions are implicit in the functioning, in the functional organization, of the infant, and are not explicitly cognized, or represented, at all.

Note again, as above, the standard tendency is to postulate that these implicit presuppositions are explicitly present in the infant as representations, as explicit beliefs, but they are not present to consciousness - they are in the Unconscious. That is, the standard tendency is to render these implicit presuppositions of the infant's functioning in the world as explicit representational belief elements or structures in the infant. The immediately ensuing question, then, of why the infant isn't aware of these beliefs, when considered at all (this question is not considered, for example, in cognitive-behavioral approaches), is handled by postulating an Unconscious place for them and a repressive mechanism for keeping them there. In other words, rendering implicit presuppositions as explicit representations - representational structures - in the agent, raises the problem of where they are and why they cannot be located, and those problems are "addressed" by positing a "place" where they are difficult to locate and a mechanism for keeping them hidden. With the recognition of implicitness, however, these issues do not arise.

It is clear that many issues standardly rendered in terms of the dynamic Unconscious are in fact phenomena of implicitness (Bickhard, 1989, in press-b). It seems likely, in fact, that most of them are. Folk psychology, and academic psychology alike, tend to construe as "beliefs" every manifested presupposition in someone's functioning: the "belief" that the floor is solid as I walk; the "belief" that trucks bearing down on me are dangerous, that red trucks bearing down on me are dangerous, that green trucks bearing down on me are dangerous, that red trucks with more than four wheels and stripes on the side bearing down on me are dangerous, ... ; the "belief" that the moon is not made of pumpernickel bread; and so on and on. Presuppositions are unbounded, so construing presuppositions as beliefs construes each of us as having an infinite number of actual beliefs (Bickhard, in press-b; Bickhard \& Terveen, 1992). Not even a dynamic Unconsciousness can handle that problem, but it's a problem that doesn't even arise so long as implicit presuppositions are recognized for themselves. What is not clear, in fact, is whether or not there is any work left for a theoretical notion of a dynamic Unconscious to do (though see Bickhard, 1980b; Christopher \& Bickhard, 1992a). We pose this 
question for consideration, but postpone addressing it for another occasion - it is peripheral to this discussion.

Another question that arises at this point concerns the nature and scope of this realm of "implicitness" that has been pointed to. In particular, are all forms of implicitness versions of implicit presuppositions? The quick answer is "No", there can also be implicit goals, motives, expectations, and so on. Consider an individual who is characteristically, but inadvertently, annoying, for example. "Being annoying" will constitute an implicit goal in his functioning without being explicitly present. For example, if I am explicitly determined to find out if, and in what way, people that I encounter are disparaging of me, I may well press and harass them to the point of angering them, thereby fulfilling my need to find out if they "in fact" dislike me - I will have an implicit goal of angering others here - I will behave "as if" that were my goal (Bickhard, 1980b; Christopher \& Bickhard, 1992a) - without there necessarily being any explicit awareness or intention of that goal. For another example, I may be so explicitly concerned with being intrusive or presumptuous with others that I wait for overt, clear invitations before joining people thus functioning with an implicit goal of distancing and being aloof. Implicitness, then, is broader than implicit presuppositions. It is a realm that has been little recognized and little explored in psychology.

\section{The Persistence and Influence of Implicitnesses}

The notion of implicitness provides a partial answer to the question of how early experience can be relevant to later personality development, of how it can be relevant to issues at higher levels of cognition: early development can involve implicit presuppositions concerning the individual and others. It raises, however, another question - the second question concerning a process approach to early influence that was mentioned above. Implicitness provides a possible relevance of early experience in a sense of implicit meaning, but the central point of implicit characteristics is that they are not ontologically actual - 'substantial' - in the infant. How then can they exert any influence on later development? They are not actually "there". In other words, we have found a way to avoid the problems of positing an early influenced substance or structure that exceeds the infant's representational capacities, but that now poses the questions of the persistence in time and the influence on later actual senses of self and others - questions that the substance and structure approaches seem to handle so directly. Substances and structures intrinsically persist, and are substantially "present" to influence later functioning.

The functional nature of interactive representation provides an answer to the question of what can be influenced in the infant, if not representational substances and structures, but raises the additional question of how such influence can be relevant. Implicitness provides the answer to that question of relevance, but the very nonsubstantiality of implicitness raises with renewed force the questions of persistence and influence on later development. We will find that the variation and selection nature of learning and development provides the answer to these questions.

Developmental Coherence. The key point to realize is that, unlike passive impressions from the environment, which are essentially independent of whatever might already be present in the mind, the processes of variation and selection constructivism are exquisitely dependent on and sensitive to the system organizations that are already present - including those that involve the critical implicit presuppositions of interest. Internal constructions are constructed out of the organizations already present; they are based upon those already available; they must functionally fit together with those that form their internal functional "environments"; and, most directly, internal constructions are differentiations and specializations of processes already present. In all of these senses, internal variation 
and selection constructions must be at least minimally consistent with those already present, otherwise they will not function together and will be selected out.

Later development, then, will tend to be coherent with, and to be specializations of, the implicitnesses of early development. This includes later explicit constructions of senses and representations of self and others that were once only implicit in the individual's functioning in the world. One important manner in which this will occur is that later reflections on the individual's own life and experience will notice and explicitly take into account properties and truths (or at least apparent-to-the-individual properties and truths) that were once only implicit. In part, this will be a process of making explicit that which was once implicit (Bickhard, 1978; Campbell \& Bickhard, 1986), including the errors of those implicitnesses; in part, it also provides a potential for noticing and changing the errors.

What is influenced in early experience, then, is the infant's manner and organization of functioning; the relevance of that influence is in terms of the implicitnesses, especially the implicit presuppositions, of that functioning; and the influence on later development is via the tendency for coherence and specialization inherent in variation and selection constructivism, and for the making explicit that which was implicit via reflection. This, then, is a set of answers to the question of early influence on later development that is consistent with a basic process ontology of mind and mental phenomena.

\section{Psychopathology}

There remains the question of the stability, the rigidity even, of psychopathological functioning - in the face of vigorous efforts to change. We will indicate the general form of the answer; a more detailed explication is available elsewhere (Bickhard, 1989).

The problem derives from the consideration that - while substance and structural approaches make psychopathological functioning persistent and rigid and difficult to change by presumption - a shift to a process ontology that is cognizant of the open system self organizing character of human beings faces not a presupposition of structural rigidity, but, instead, a prima facie problematicness of how such a dynamic, in-process, always changing system could even in principle get stuck in a form of pathological functioning. In other words, how is the stability presupposition of substance approaches satisfied when the actual ontology is process and change; how could substance and structural approaches ever seem to be appropriate at all? With respect to the sense in which psychopathology is rigidity of functioning, this question becomes one of the logical possibility of psychopathology in an intrinsically self organizing system.

Auto-protectiveness. The central idea in the answer to this problem is to note that both the interactions and the self organizing variational constructions of the system are guided by the system itself. If the organization of the system were such that that guidance in some way prohibited the very sorts of self organizing activities that would be required to change that organization, then that organization would in effect protect itself from change. It would constitute an auto-protective way of being in the world. Note that this autoprotectiveness is not necessarily an actual goal, but rather an implicit goal - an effect - of the underlying organization of functioning. For example, a man who feels that his sense of self respect is constantly on the line and threatened by potential failure of manly strength is going to find it very difficult to engage in the honest self examination of his thoughts and feelings - and fears and weaknesses - that would be required to change this basically macho orientation to the world. The autoprotectiveness is implicit in, is emergent in, his explicit vigilance for weakness, and is not explicitly present anywhere. 
Autoprotectiveness, then, is the central sense in which rigidity of functioning is possible even for a system intrinsically always in process and always engaged in selforganization. It is the initial answer to the problem of psychopathology from within a process ontology of mind.

Autoprotectiveness, however, is itself a functional emergent of underlying processes. It is not an explicit process itself. The explication of what sorts of actual functioning will manifest autoprotectiveness, and, thus, psychopathological rigidity, remains to be examined. It turns out that autoprotective functioning intrinsically involves emotions - phenomena not addressed in this paper - negative emotions, terrors, in fact, and it involves the self in ways that converge interestingly with many intuitions and observations in the clinical literature. Terrifying senses of the actuality or potentiality of self inadequacy are at the core of psychopathology. Autoprotectiveness, however, is sufficient in itself to the purposes of this paper; the more detailed explication is already available (Bickhard, 1989).

The fundamental point is that autoprotectiveness constitutes a manner in which even a system with a basic ontology of process and change could nevertheless manifest rigidity of functioning. Autoprotectiveness is a condition in which processes of variation and selection self-organization can be internally debilitated. Most specifically, autoprotectiveness provides a process level explanation of the persistence of dysfunctional living in the face of extreme misery and desperate efforts to change.

\section{Summary}

Substance ontologies are common in the early histories of all of the sciences. Psychology is still caught in that phase of its history - substance ontologies, however, are not justified by contemporary science. Substances appeal because they have an aptness whenever we encounter phenomena with some sort of persistence through time and resistance to change. This aptness, unfortunately, is one of presupposition rather than explanation. It gives a sense of explanation, when in fact it diverts attention from the real problems of understanding involved.

Two issues in personality development focus these problems of substance approaches. Both the problem of the influence of early experience and the problem of psychopathological rigidity involve properties of persistence and rigidity, and both are given a semblance of reasonableness in contemporary substance approaches to personality development precisely in terms of the stability presuppositions of those substance approaches. The presuppositions of those approaches, however, preclude any genuine explanatory attempts - the most central characteristics to be explained are presupposed instead of being posed as problematic.

A shift to a recognition of the intrinsic process and self-organizing ontology of human beings, on the other hand, brings the stabilities involved directly to the fore: how can ever-changing process manifest the sorts of stabilities and persistences and rigidities involved?

The first step is to recognize that the constructions of the functional ways of being of an infant will involve implicit presuppositions about self, about the world, about others in it, and so on, without having to postulate cognitive capacities of the infant that are simply 
not present. $^{2}$ The constructions of infants, thus — and, therefore, their experiences have relevance for later personality development.

The very implicitness that solves the problem of the relevance of infant constructions and experience, however, poses with particular force the problem of influence on later development. If it's not really "there" — substantial - how does it influence later development?

The coherence and specialization character of variation and selection constructivism provides the answer to this question. The implicitnesses tend to persist because the system organizations in which those implicitnesses inhere constrain all further construction. Further system construction must be consistent with already existing system organization - and, thus, with the implicit functional presuppositions of those system organizations otherwise they will be functionally incompatible, and will be selected out. Layers of implicitnesses, furthermore, will tend to become explicit in further reflective constructions later in development.

At this point the question is raised of how much of the phenomena standardly relegated to the classic dynamic Unconscious are in fact phenomena of implicitness instead. The question is not pursued far here, but the suggestion is made that much of what is usually construed as Unconscious is instead implicit. That is, the dynamic Unconscious is an invented, metaphorical, location for substance approaches to implicitnesses.

The problem of psychopathology takes on a special force from within a process ontology because it is not only a stability of functioning, it is a rigidity of functioning often in the face of massive, motivated, creative attempts to change. The general form of the answer of how such rigidity is possible is the implicit function of autoprotectiveness.

Substance and structure ontologies have nothing to recommend them in contemporary science. They are nevertheless still dominant in psychology. A shift to a process ontology of mind can fundamentally change the nature of the problems to be solved and the sorts of answers potentially available to answer them. We have examined two instances, two case studies, of that in the field of personality development.

2 The approach outlined here is a functionalist one - representation and early influence are construed in terms of functional organizations in agents and in terms of processes within such functional organizations. This is not functionalism in its standard contemporary sense, however (Bickhard, in press-a): functionalism as an approach to mental phenomena standardly construes functional processes as operations of formal programs on formal encoded symbols (e.g., Fodor, 1987, 1990). There are many problems with such construals, but it suffices here to point out that the reliance on encodingism in such approaches is itself a violation of a process ontology — representation cannot be explicated within an atomistic substance metaphysics. 


\section{References}

Annas, J., \& Barnes, J. (1985). The modes of scepticism. Cambridge: Cambridge University Press.

Beck, A. T. (1976). Cognitive therapy and the emotional disorders. New York: International Universities Press.

Beck, A. T., \& Weishaar, M. (1989). Cognitive therapy. In A. Freeman, K. M. Simon, L. E. Beutler, \& H. Arkowitz (Eds.), Comprehensive handbook of cognitive therapy (pp. 21-36). New York: Plenum.

Bickhard, M. H. (1978). The nature of developmental stages. Human Development, 21, 217-233.

Bickhard, M. H. (1980). Cognition, convention, and communication. New York: Praeger. (a)

Bickhard, M. H. (1980). Functionalism in Adlerian psychology. Journal of Individual Psychology, 36, 66-74. (b)

Bickhard, M. H. (1987). The social nature of the functional nature of language. In M. Hickmann (Ed.), Social and functional approaches to language and thought (pp. 39-65). New York: Academic.

Bickhard, M. H. (1988). Piaget on variation and selection models: Structuralism, logical necessity, and interactivism Human Development, 31, 274-312.

Bickhard, M. H. (1989). The nature of psychopathology. In L. Simek-Downing (Ed.), International psychotherapy: Theories, research, and cross-cultural implications (pp. 115-140). New York: Praeger.

Bickhard, M. H. (1991). How to build a machine with emergent representational content. CogSci News, 4, 1-8. (a)

Bickhard, M. H. (1991). Homuncular innatism is incoherent: A reply to Jackendoff. The Genetic Epistemologist, 19, 5. (b)

Bickhard, M. H. (1991). The import of Fodor's anti-constructivist argument. In Les Steffe (Ed.), Epistemological foundations of mathematical experience (pp. 14-25). New York: Springer-Verlag. (c)

Bickhard, M. H. (1992). How does the environment affect the person? In L. T. Winegar, \& J. Valsiner (Eds.), Children's development within social contexts: Metatheory and theory (pp. 63-92). Hillsdale, NJ: Lawrence Erlbaum. (a)

Bickhard, M. H. (1992). Scaffolding and self scaffolding: Central aspects of development. In L. T. Winegar, \& J. Valsiner (Eds.), Children's development within social contexts: Research and methodology (pp. 33-52). Hillsdale, NJ: Lawrence Erlbaum. (b) 
Bickhard, M. H. (1992). Commentary on the age 4 transition. Human Development, 35, 182-192. (c)

Bickhard, M. H. (in press-a). Representational content in humans and machines. Journal of Experimental and Theoretical Artificial Intelligence. And in K. Ford, \& C. Glymour (Eds.), Android epistemology. Greenwich, CT: JAI Press.

Bickhard, M. H. (in press-b). Levels of representationality. In C. Glymour (Ed.), Proceedings of a Conference on Methodological Issues in Cognitive Science.

Bickhard, M. H., \& Campbell, R. L. (1989). Interactivism and genetic epistemology. Archives de Psychologie, 57, 99-121.

Bickhard, M. H., \& Campbell, R. L. (1992). Some foundational questions concerning language studies: With a focus on categorial grammars and model theoretic possible worlds semantics. Journal of Pragmatics, 17, 401-433.

Bickhard, M. H., \& Richie, D. M. (1983). On the nature of representation: A case study of James J. Gibson's theory of perception. New York: Praeger.

Bickhard, M. H., \& Terveen, L. (1992). The impasse of artificial intelligence and cognitive science. Manuscript.

Bowlby, J. (1973). Separation. New York: Basic.

Bowlby, J. (1982). Attachment and loss: Retrospect and prospect. American Journal of Orthopsychiatry, 52, 664-678.

Bretherton, I., Ridgeway, D., \& Cassidy, J. (1990). Assessing internal working models of the attachment relationship. In M. Greenberg, D. Cicchetti, \& E. M. Cummings (Eds.), Attachment during the preschool years: Theory, research, and intervention (pp. 273-308). Chicago: University of Chicago Press.

Brown, H. R., \& Harré, R. (1988). Philosophical foundations of quantum field theory. Oxford: Oxford University Press.

Burnyeat, M. (1983). The skeptical tradition. Berkeley: University of California Press.

Campbell, D. T. (1974). Evolutionary epistemology. In P. A. Schilpp (Ed.), The philosophy of Karl Popper (pp. 413-463). LaSalle, IL: Open Court.

Campbell, R. L., \& Bickhard, M. H. (1986). Knowing levels and developmental stages. Basel: Karger.

Campbell, R. L., \& Bickhard, M. H. (1987). A deconstruction of Fodor's anticonstructivism Human Development, 30, 48-59.

Campbell, R. L., \& Bickhard, M. H. (1992). Clearing the ground: Foundational questions once again. Journal of Pragmatics, 17, 557-602.

Chomsky, N. (1964). A review of B. F. Skinner's Verbal Behavior. In J. A. Fodor, \& J. J. Katz (Eds.), The structure of language. Englewood Cliffs, NJ: PrenticeHall. 
Christopher, J. C., \& Bickhard, M. H. (1992). Otto Kernberg's object relations theory: A critical examination. Manuscript. (b)

Christopher, J. C., \& Bickhard, M. H. (1992). Remodeling the As If in Adler's concept of the life style. Journal of Individual Psychology, 48, 76-85. (a)

Christopher, J. C., \& Bickhard, M. H. (in press). Cognitive constraints on object relations theory. Theory and Psychology.

Christopher, J. C., Bickhard, M. H., \& Lambeth, G. S. (in press). Splitting Kernberg: A critique of Otto Kernberg's notion of splitting. Psychotherapy.

Eagle, M. (1984). Recent developments in psychoanalysis. New York: McGraw-Hill.

Ellis, A. (1962). Reason and emotion. New York: Lyle Stuart.

Fodor, J. A. (1987). Psychosemantics. Cambridge, MA: MIT Press.

Fodor, J. A. (1990). A theory of content and other essays. Cambridge, MA: MIT Press.

Fodor, J. A., \& Pylyshyn, Z. (1981). How direct is visual perception?: Some reflections on Gibson's ecological approach. Cognition, 9, 139-196.

Fodor, J. A., Bever, T. G., \& Garrett, M. F. (1974). The psychology of language. New York: McGraw-Hill.

Gratch, G. (1977). Review of Piagetian infancy research: Object concept development. In W. F. Overton, \& J. M. Gallagher (Eds.), Knowledge and development (pp. 59-91). New York: Plenum.

Greenberg, J., \& Mitchell, S. (1983). Object relations in psychoanalytic theory. Cambridge: Harvard University Press.

Harris, P. L. (1983). Infant cognition. In P. H. Mussen (Ed.), Handbook of child psychology. Volume II: Infancy and developmental psychobiology (pp. 689-782). M. M. Haith, \& J. J. Campos (Volume Eds.) New York: Wiley.

Hull, D. (1974). Philosophy of biological science. Englewood Cliffs, NJ: Prentice-Hall.

Kobak, R. R., \& Sceery, A. (1988). Attachment in late adolescence: Working models, affect regulation, and representation of self and others. Child Development, 59, $135-146$.

Loewer, B., \& Rey, G. (1991). Meaning in mind: Fodor and his critics. Oxford: Blackwell.

Lucas, G. R. (1983). The genesis of modern process thought. London and Metuchen, NJ: Scarecrow Press.

Lucas, G. R. (1989). The rehabilitation of Whitehead. Albany, NY: S.U.N.Y.

Meichenbaum, D. (1977). Cognitive-behavior modification. New York: Plenum. 
Nelson, K. (1992). Emergence of autobiographical memory at age 4. Human Development, 35, 172-177.

Nicolis, G., \& Prigogine, I. (1977). Self-organization in nonequilibrium systems. New York: Wiley.

Palmer, S. E. (1978). Fundamental aspects of cognitive representation. In E. Rosch \& B. B. Lloyd (Eds.), Cognition and categorization (pp. 259-303). Hillsdale, NJ: Lawrence Erlbaum.

Piaget, J. (1970). Genetic epistemology. New York: Columbia.

Piaget, J. (1971). Biology and knowledge. Chicago: University of Chicago.

Piaget, J., \& Inhelder, B. (1969). The psychology of the child. New York: Basic.

Popkin, R. H. (1979). The history of scepticism. Berkeley: University of California Press.

Prigogine, I. (1980). From being to becoming. San Francisco: Freeman.

Reppen, J. (1985). Beyond Freud. Hillsdale, NJ: Lawrence Erlbaum.

Rychlak, J. F. (1981). Introduction to personality and psychotherapy. (2nd ed). Boston: Houghton Mifflin.

Schilpp, P. A. (Ed.) (1951). The philosophy of Alfred North Whitehead. LaSalle, IL: Open Court.

Sulloway, F. J. (1979). Freud: Biologist of the mind. New York: Basic.

Teller, P. (1990). Prolegomenon to a proper interpretation of quantum field theory. Philosophy of Science, 57, 594-618.

Tulving, E. (1985). How many memory systems are there. American Psychologist, 40, 385-398. 